Article

\title{
Simulation Analysis of Erosion-Corrosion Behaviors of Elbow under Gas-Solid Two-Phase Flow Conditions
}

\author{
Qunfeng Zeng*(D) and Wenchuang Qi
}

Key Laboratory of Education Ministry for Modern Design and Rotor-Bearing System, Xi'an Jiaotong University, Xi'an 710049, China; qwch61@stu.xjtu.edu.cn

* Correspondence: qzeng@xjtu.edu.cn

Received: 26 July 2020; Accepted: 16 September 2020; Published: 22 September 2020

\begin{abstract}
In the production and gathering process of coal gas, the complex composition of the coal gas, harsh environments, the complex medium, and high content of solid particles in slurry cause the equipment malfunctions and even failure because of erosion and corrosion. In the present study, COMSOL multi-physics finite element simulation software is used to simulate the erosion-corrosion behaviors of elbow in key chemical equipments. The electrochemical corrosion, solid particle erosion, chemical reaction, and turbulent flow are coupled together. The particle count method is proposed to clarify the erosion phenomenon. The simulation results show that particles with high turbulent intensity hit the wall of elbow directly, which forms a slanted elliptical erosion zone on the extrados surface at $40^{\circ}-50^{\circ}$. The chemical reaction in turbulence has a difference in the concentration distribution of substances, and this phenomenon leads to different magnitudes of the corrosion current densities in the tube. Moreover, 1/6 released particles hit the extrados surface of the elbow. These findings are beneficial to understand the erosion-corrosion phenomena and design the elbow in key chemical equipment.
\end{abstract}

Keywords: elbow erosion; turbulence flow; gas-solid flow; corrosion; numerical simulation

\section{Introduction}

Erosion-corrosion is a comprehensive type of the failure process including the mechanical and electrochemical action [1]. The erosion-corrosion phenomena exist in many industries; however, especially in the chemical industry, serious accidents and economic losses occur easily because of the harsh working environments, corrosion, and other reasons. In 2016, an explosion caused by the leakage of the oil pipeline in the southern Gulf of Mexico's National Oil Company caused serious casualties and economic losses. Most pipelines of the coal chemical industry are made of carbon steel, which are seriously corroded by the working and environmental medium during operation [2]. For the erosion-corrosion problems, many researchers have conducted simulation studies. However, researchers performed only CFD simulation analysis, and the velocity vector of the flow filed is used to characterize the serious position of erosion [3]. In these researches, there were no comprehensive simulated erosion failure processes, such as electrochemical corrosion through current density or mass loss per unit area. Based on CFD model, the researchers have further simulated the failure process of particle erosion without electrochemical corrosion and obtained the trajectory of the particles hitting the wall [4]. Mass loss per unit area and the quantities of particles hitting the wall of elbow have not yet been obtained. Zeng et al. [5] have simulated the corrosion current density distribution of electrochemistry without the erosion and chemical reaction and acquired the galvanic current density. An erosion-corrosion simulation model involving the erosion, electrochemical corrosion, and chemical 
reaction under the turbulent flow condition has been rarely reported. The reason may be that the CFD analysis involves a difficult process and CFD coupling erosion or electrochemical corrosion is also difficult to develop. The corrosion module in COMSOL Multiphysics features built-in interfaces, features, and examples for modeling and analyzing these different types of corrosion. The chemical reaction of steel and fluid is simulated by chemical corrosion module, which allows us to simulate all electrochemical corrosion processes. A large amount of information can be obtained, including electrochemical reactions, potentials in electrolytes and metal structures, homogeneous chemical reactions, and unique phenomena in the corrosion process. The output of such an analysis is the localized current density, which is used to calculate the average corrosion rate of any component over a given period of time. It is also possible to observe the impact of environmental variables. Simulation analysis can assist in the identification of corrosion-related problems.

The aim is to simulate the erosion-corrosion behaviors of elbow involving the erosion of particles, electrochemical corrosions of the dissolved iron and hydrogen evolution, turbulence and chemical reactions of carbonic acid ionization simultaneously in the present paper. The complex situations in tube are simplified to gas-solid two-phase flow with the chemical reactions and electrochemical reactions, and the gas is a mixture of syngas and carbon dioxide. The Finnie's erosion model is proposed to analyze the erosion of sulfur particles eroding wall through the probability of the quantities of particles and mass loss per unit area. It is expected to obtain the turbulence characteristics, substance concentration distribution, electrochemical corrosion current density, the quantities of particles striking the wall and mass loss per unit area. The turbulent characteristics of gas in elbow and the erosion failure process of particles hitting the elbow wall are simulated under turbulence condition. The effect of turbulence on the substance concentration distribution and the substance concentration distribution on the electrochemical corrosion process of hydrogen evolution reaction and iron dissolution reaction are investigated systemically. Finally, the mechanism of different physical and chemical fields on the key parts of high temperature and pressure pipeline during operation is investigated, and the simulation model of the corrosion under the multi-field coupling actions is built. The stress, temperature, and corrosion cracks of the key parts of the pipeline between corrosion development and status are achieved, and the corrosion leakage prediction model is established and the corrosion development trend and prediction method of leakage occurrence location is predicted.

\section{Simulation Model}

\subsection{Simplification of Chemical Equipment}

Figure 1 shows a schematic diagram about the vulnerable elbow in the coal chemical plant. First, the coal-water slurry is reacted with oxygen to form the mixture gas of syngas $(60 \%)$ and $\mathrm{CO}_{2}(40 \%)$ at the temperature of $1350{ }^{\circ} \mathrm{C}$. Second, the mixture gas is cooled and the temperate decreases to $250{ }^{\circ} \mathrm{C}$ in the quench chamber. Finally, the mixture gas is departed from the quench chamber and introduced into the transmission pipeline at high speed flow with solid contaminants (sulfur-containing fly ash) eroding the wall. $\mathrm{CO}_{2}$ is dissolved in water forming the saturated carbonic acid solution that results in the electrochemical corrosion of the pipeline under the operational service or out of service conditions. The erosion-corrosion phenomena around the elbow may lead to the serious leakage under the harsh working environments.

\subsection{Geometry}

Three-dimensional model is built to investigate the erosion-corrosion process of elbow. Figure 2 shows a planar graph of the $90^{\circ}$ elbow with two straight sections, four featured edges and two featured surfaces (without size scale). The lines with color are used to indicate the feature edges of the tube and analyze the process of erosion-corrosion. The diameter $(D)$ of pipeline is $600 \mathrm{~mm}$. A curvature ratio of elbow, which is the ratio of a curvature radius of the centerline to that of interior edge of the elbow, is 1.5 (dimensionless). Flow is input into the first straight section $\left(L_{1}=3000 \mathrm{~mm}\right)$ in length at the top 
left corner of the figure, with a $90^{\circ}$ elbow section and the second straight section of pipe $\left(L_{2}=3000\right.$ $\mathrm{mm}$ ) in length in sequence.

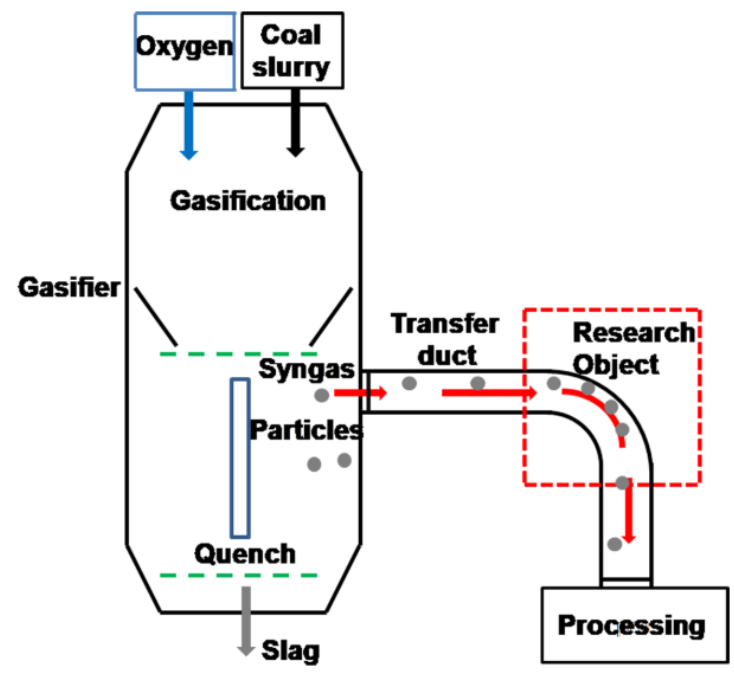

Figure 1. Schematic of chemical equipment.

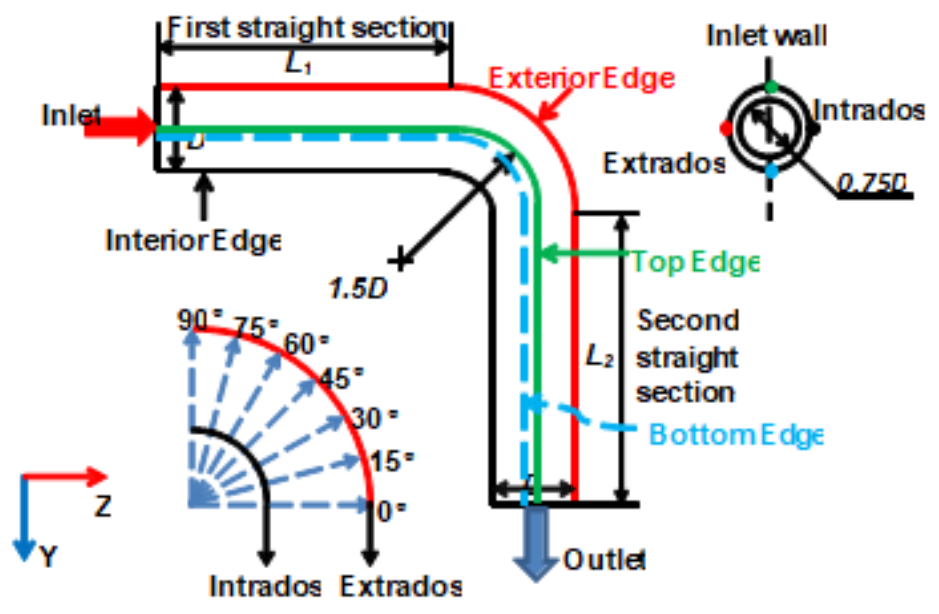

Figure 2. Schematic diagram of pipeline.

\subsection{Mesh}

The unstructured meshes are constructed in the computational domain. An example mesh of the pipeline is shown in Figure 3. The free triangular grid is constructed the inlet boundary $(0.75 D)$. The sweep mesh is adopted because of the long narrow pipe structures and the grid processor along the pipeline to generate the structured quadrangle mesh (generate hexahedron). A boundary layer grid with 25 layers and 1.25 stretch factors is used to discretize the tube in order to ensure adequate analysis of fluid flow and particle erosion behavior near the tube wall.

Three kinds of meshes (as shown in Table 1) are constructed for the present model to test the dependence of the numerical simulation results on the mesh resolution at the same initial boundary conditions and improve the accuracy of the simulation. The variation of the max fluid velocity with the mesh resolution is examined. The results are shown in Table 1. It is found that the differences of the calculated maximum value of fluid velocity among the three meshes are very small. Thus, the first mesh method is used in this paper to reduce the calculation time. 
In thin film flow, the shell interface is used to solve the Reynolds equation for flow in narrow structures and the mass and momentum balances are used to formulate with a function across the thickness of the thin structure, which indicates that the thickness does not have to be meshed. This functionality helps avoid meshing problems across the gap and thereby saves computation time.

Table 1. Mesh dependence tests.

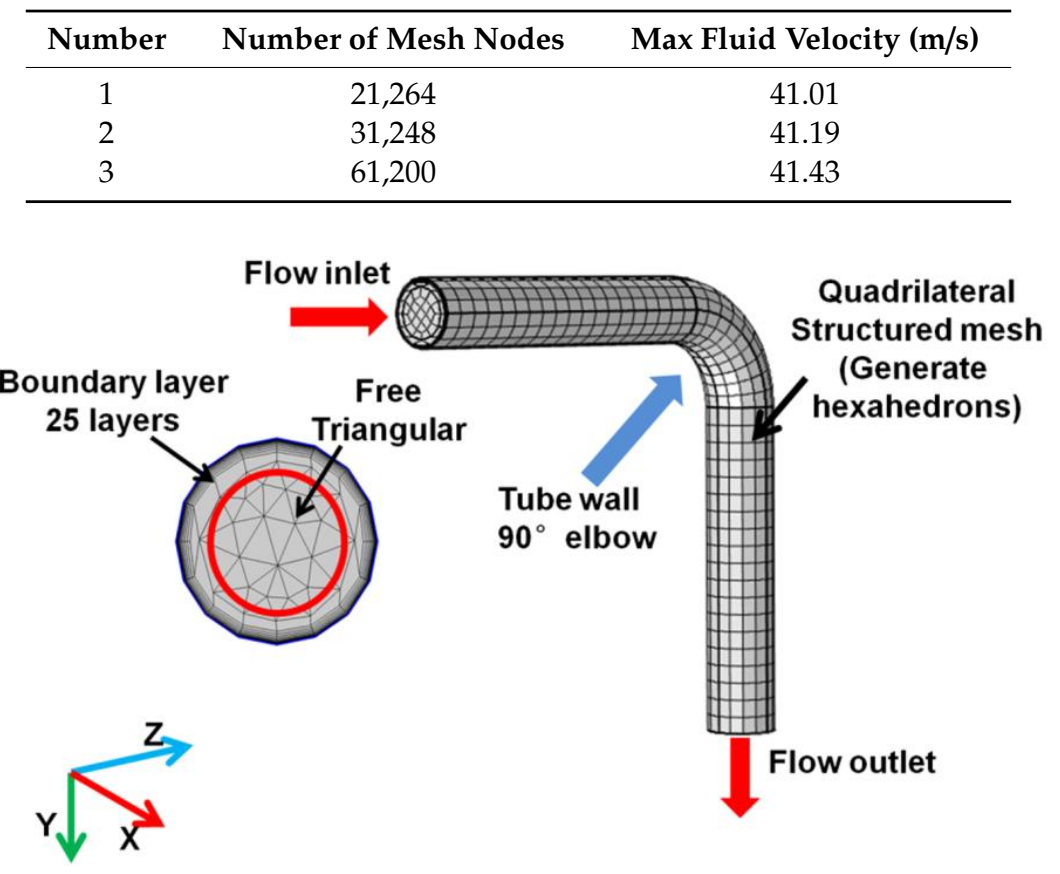

Figure 3. Mesh profile of pipeline.

\subsection{The Mathematical Simulation Model}

The numerical simulation model is built by a steady state solver, and then the erosion of particles is calculated by a transient solver. There are five physical field interfaces and two multi-physics interfaces in the model: turbulent flow (spf), particle tracking for fluid flow ( fpt), chemistry (chem), secondary current distribution (siec), transport of diluted species ( $t d s)$, fluid-particle interaction (fpi), and flow coupling $\left(f_{c}\right)$. The chem interface is a physical field interface in the numerical simulation software, and the siec interface as same.

\subsubsection{Turbulence}

The motion of gas is simplified to the impressible and isothermal flow according to the process conditions and gas characteristics. The $\mathrm{k}-\varepsilon$ model is based on the equation model and introduced an equation about the turbulent dissipation rate. The calculation is small but there is more data accumulation. It has a wide range of industrial applications with the good accuracy and good convergence. The Reynolds-Averaged Navier-Stokes (RANS) k- $\varepsilon$ model is used to simulate and analyze the turbulence. The equations are solved on the basis of RANS equations for conservation of momentum and the continuity equation for conservation of mass in the spf interface. The effects of the turbulence flow are modeled through two equations-turbulent kinetic energy $k$ and dissipation rate $\varepsilon$ with the reliability constraints. The flow near wall is described by the wall functions. Gas is represented by a continuous phase of Euler's method and discretized using P1+P1 method. Two advanced algorithms of the streamline diffusion and crosswind diffusion are applied to the Navier-Stokes equations and turbulence equations to converge the model easily. The pseudo-time stepping algorithm is used to solve the stationary equation. The velocity of the CFL digital expression of the turbulence variable ratio parameter is $1 \mathrm{~m} / \mathrm{s}$ and the length scale factor is 0.035 . The specific parameters of 
the turbulence model are $C_{\mathrm{e} 1}=1.44, C_{\mathrm{e} 2}=1.92, C_{\mu}=0.09, \sigma_{\mathrm{k}}=1, \sigma_{\mathrm{c}}=1.3, \kappa_{\mathrm{v}}=0.41, B=5.24$. These parameters are RANS k- $\varepsilon$ model constants. The governing equations of the turbulent flow are as follows.

Incompressible flow equation in steady state:

$$
\begin{gathered}
\rho(U \cdot \nabla) U=\nabla \cdot\left[-P I+\left(\mu+\mu_{T}\right)\left(\nabla U+(\nabla U)^{T}\right)\right]+F \\
\rho \nabla \cdot(u)=0
\end{gathered}
$$

The transport equation of $k$ :

$$
\rho(u \cdot \nabla) k=\nabla \cdot\left[\left(\mu+\frac{\mu_{T}}{\sigma_{k}}\right) \nabla k\right]+P_{k}-\rho \varepsilon
$$

where the production term and the turbulent viscosity are listed as following:

$$
p_{k}=\mu_{T}\left[\nabla U:\left(\nabla U+(\nabla U)^{T}\right)\right] \quad \mu_{T}=\rho C_{u} \frac{k^{2}}{\varepsilon}
$$

The transport equation of $\varepsilon$ :

$$
\rho(U \cdot \nabla) \varepsilon=\nabla \cdot\left[\left(\mu+\frac{\mu_{T}}{\sigma_{\varepsilon}}\right) \nabla \varepsilon\right]+C_{\varepsilon 1} \frac{\varepsilon}{k} P_{k}-C_{\varepsilon 2} \rho \frac{\varepsilon^{2}}{k} \quad \varepsilon=e p
$$

where $\mu_{T}, \mu, \rho, P, U, I, F, k, \varepsilon, \sigma_{k}$, and $P_{k}$, stand for the eddy viscosity, viscosity, density, pressure, velocity vector, unit matrix, volume force vector, turbulent kinetic energy, turbulent dissipation rate, respectively. The SI unit is used.

\subsubsection{Erosion}

The sulfur particles are considered as the discrete phases in the fpt interface during simulation. The movement of particles under the framework of Lagrange is governed by Newton's second law (6) and affected by the drag force, gravity, and brown force. The drag force (7) is generated by the speed difference between gas and particles and controlled by stokes' law (8). In addition, the body force (9) formed by the effect of accelerated or decelerated particles on the movement of gas is obtained through gas-particles interaction in the fpi interface, and then the gas velocity in the spf interface and particles velocity in the $f p t$ interface are coupled by gas-particles interaction. Through sampling and analysis of the pipe ash, and in order to simplify the particle model, all sulfur particles, releasing 500 particles per $0.08 \mathrm{~s}$ at the boundary of inlet, are introduced into the tube by high-speed gas and there are the same physical properties of density $\left(2360 \mathrm{~kg} / \mathrm{m}^{3}\right)$, diameter $(50 \mu \mathrm{m})$, and shape (sphere). The turbulent dispersion model of particles adopts discrete random walk, the variable time step method. The turbulent kinetic energy and turbulent dissipation rate of particles are coupled to those of gas in the spf interface. In addition, there is still no recognized universally applicable theoretical model due to the complexity of the erosion behavior of material. To assess the interaction between particles and pipes, Finnie erosion model is used to explain the rule of the particle erosion of plastic materials at low impact angles, thus the classical Finnie erosion model (10) is used to describe the impact of particles and the count method is used to count the quantities of particles hitting the wall considering the shape of the pipeline model. The ratio of the normal and tangential force and number multiplication factor are set to 1 . The surface hardness of wall is $640 \mathrm{~N} / \mathrm{mm}^{2}$ and the surface mass density is $7.98 \mathrm{~g} / \mathrm{cm}^{3}$ respectively.

Newton's second law and drag force equation:

$$
\frac{\mathrm{d}\left(m_{p} v\right)}{d t}=F_{D}+F_{g}+F_{b r o w n}
$$




$$
F_{D}=\left(\frac{1}{\tau_{P}}\right) m_{P}(u-v)
$$

where, $F_{D}$ is Drag force, $F_{g}$ is gravity, and $F_{\text {brown }}$ is brown force. The $m_{p}$ is the particle mass (SI unit: $\mathrm{kg}$ ), $\tau_{p}$ is the particle velocity response time (SI unit: $\mathrm{s}$ ), $V$ is the velocity of particle (SI unit: $\mathrm{m} / \mathrm{s}$ ), and $U$ is the fluid velocity (SI unit: $\mathrm{m} / \mathrm{s}$ ).

The stokes drag law for the particle response time is defined as:

$$
\tau_{P}=\frac{\rho_{P} d_{P}^{2}}{18 \mu}
$$

where, $\mu$ is the fluid viscosity (SI unit: Pa.s), $\rho_{p}$ is the particle density (SI unit: $\mathrm{kg} / \mathrm{m}^{3}$ ), and $d_{p}$ is the particle diameter (SI unit: $\mathrm{m}$ ).

Body force of particle-to-syngas calculation equation:

$$
F_{V, j}=-\frac{1}{V_{j}} \sum_{i=1}^{N} n_{i} F_{D, i} \int \delta\left(r-q_{i}\right) d V
$$

where, $F_{v, j}$ is the average volume force, a mesh element $j$ with volume $V_{j}, \delta$ is the Dirac delta function, $F_{D, i}$ is the drag force exerted on the $i$ th particle, $n_{i}$ is the force multiplication factor of the $i$ th model particle, and $N$ is the total number of particles.

The Finnie erosion equation is listed [6].

$$
\begin{gathered}
V=\frac{c M U^{2}}{4 p\left(1+\frac{m r^{2}}{I}\right)}\left[(\cos \alpha)^{2}\right] \quad \tan \alpha>\frac{P}{2} \\
V=\frac{c M U^{2}}{4 p\left(1+\frac{m r^{2}}{I}\right)} \frac{2}{p}\left[\sin (2 \alpha)-2 \frac{(\sin \alpha)^{2}}{p}\right] \quad \tan \alpha \leq \frac{P}{2}
\end{gathered}
$$

where, $c$ (dimensionless) is the fraction of particles cutting in an idealized manner; $M$ (SI unit: $\mathrm{kg}$ ) is the total mass of eroding particles; $U(\mathrm{~m} / \mathrm{s})$ is the magnitude of the incident particle velocity; $p(\mathrm{~Pa})$ is the Vickers hardness of the material; $m$ (SI unit: $\mathrm{kg}$ ) is the mass of an individual particle hitting the surface; $r$ (SI unit: $\mathrm{m}$ ) is the average particle radius; $I$ (SI unit: $\mathrm{kg} / \mathrm{m}^{2}$ ) is the moment of inertia of an individual particle about its center of mass. For an isotropic sphere, $I=2 \mathrm{mr}^{2} / 5 ; \alpha(\mathrm{rad})$ is the angle of incidence, with $\alpha=0$ tangent to the surface and $\alpha=\pi / 2$ normal to the surface; $P$ is a dimensionless parameter, defined as $P=K /(1+2 m r / I)$ and $K$ (dimensionless) is the ratio of vertical and horizontal forces action on the particle. The mass loss per unit area vs. time is chosen to evaluate the erosion rate of steel.

\subsubsection{Chemical Reaction and Electrochemical Corrosion}

The ionization reactions of carbonic acid are generated into the hydrogen ion and bicarbonate ions, in the chem interface, and the distribution of the substance concentration is affected by diffusion and convection in the $t d s$ interface [7]. Table 2 shows reaction equilibrium constant, positive reaction rate, and diffusion coefficient. The convection is coupled by the turbulent mixing and affected by the motion of gas depending on the mass balance Equation (11). Turbulent kinematic viscosity of substance under turbulence is governed by that of turbulent gas, and turbulent Schmidt number is 0.71 .

Electrochemical corrosion is described by the reactions of dissolved iron and hydrogen evolution in the siec interface. The iron dissolution reaction $\left(\mathrm{Fe}^{2+}+2 \mathrm{e}^{-} \rightarrow \mathrm{Fe}\right)$ governed by anode Tafel Equation (12) occurred on the wall, and the hydrogen evolution reaction $\left(2 \mathrm{H}^{+}+2 \mathrm{e}^{-} \rightarrow \mathrm{H}_{2}\right)$ controlled by concentration-dependent kinetic Equation (13) occurred on the inner surface of the tube. The interface of metal/electrolyte is considered to be an electrode-electrolyte coupled wall to complete charge transfer and charge conservation between ions and electrons. The electrolyte conductivity is $2.5 \times 10^{-3} \mathrm{~S} / \mathrm{m}$. The temperature in the pipeline is $250^{\circ} \mathrm{C}$. The concentration of $\mathrm{Fe}^{2+}$ is $1 \times 10^{-9} \mathrm{~mol} / \mathrm{L}$. So, the concentration of $\mathrm{H}^{+}$is calculated by the Nernst equation, the $\mathrm{H}^{+}$concentration value is $1 \times 10^{-6} \mathrm{~mol} / \mathrm{L}$. According to calculation, the initial potential of electrolyte is $\mathrm{E}_{\mathrm{eq}, \mathrm{Fe}}=-0.9068 \mathrm{~V}$, 
and the initial potential of electrode is $0 \mathrm{~V}$. The exchange current density and Tafel slope of iron dissolved reaction are $10^{-3} \mathrm{~A} / \mathrm{m}^{2}$ and $40 \mathrm{mV}$ per decade [8], respectively. Normally, anodic oxidation of iron presents a Tafel slope of less than $60 \mathrm{mV}$. The equilibrium potential depends on Equation (14). The exchange current density of hydrogen evolution reaction is $1.1 \times 10^{-2} \mathrm{~A} / \mathrm{m}^{2}$. The equilibrium potential is $-0.3112 \mathrm{~V}$.

Mass balance equation is:

$$
\frac{\partial c_{i}}{\partial t}+\nabla \cdot\left(-D \nabla c_{i}\right)+U \cdot \nabla c_{i}=R_{i}
$$

where, $C_{i}$ is the concentration of the species (SI unit: $\mathrm{mol} / \mathrm{m}^{3}$ ), $D_{i}$ is the diffusion coefficient (SI unit: $\mathrm{m}^{2} / \mathrm{s}$ ), $R_{i}$ is a reaction rate expression for the species (SI unit: $\mathrm{mol} /\left(\mathrm{m}^{3} \cdot \mathrm{s}\right)$ ), and $U$ is the velocity vector (SI unit: $\mathrm{m} / \mathrm{s}$ ).

Anode Tafel equation:

$$
i_{l o c}=i_{0} \times 10^{\frac{\eta}{A_{a}}}
$$

where, $i_{l o c}$ denotes the local charge transfer current density, $i_{0}$ denotes the exchange current density, and $A_{a}$ denotes the Tafel slope.

Concentration-dependent kinetics:

$$
i_{l o c}=i_{0}\left[C_{R} \exp \left(\frac{\alpha_{a} F \eta}{R T}\right)-C_{O} \exp \left(\frac{-\alpha_{a} F \eta}{R T}\right)\right]
$$

where, $i_{l o c}$ denotes the local charge transfer current density, $i_{0}$ is the exchange current density, $C_{R}$ and $\mathrm{C}_{\mathrm{O}}$ are dimensionless expressions, describing the dependence on the reduced and oxidized species in the reaction.

$$
\mathrm{E}_{\mathrm{eq}, \mathrm{Fe}}=-0.44+2.303 \frac{\mathrm{RT}}{2 F} \times \log \left(10^{-9}\right)
$$

where, $\mathrm{R}$ is the gas constant, $\mathrm{T}$ is the absolute temperature in Kelvin, $\mathrm{F}$ is Faraday's constant. The $\mathrm{Fe}^{2+}$

\begin{tabular}{|c|c|}
\hline Constant & Source \\
\hline$K_{c a}=387.6 \times 10^{-\left(6.41-1.594 \times 10^{-3} \cdot T_{f}+8.52 \times 10^{-6} \cdot T_{f}^{2}-3.07 \times 10^{-5} \cdot p\right)} \mathrm{mol}$ & Oddo and Tomson [9] \\
\hline 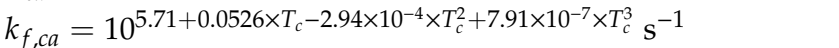 & Comprehensive chemical kinetics \\
\hline$K_{b i}=10^{-\left(10.61-4.97 \times 10^{-3} \cdot T_{f}+1.331 \times 10^{-5} \cdot T_{f}^{2}-2.624 \times 10^{-5} \cdot P\right)} \mathrm{mol}$ & Oddo and Tomson \\
\hline$k_{f, b i}=10^{9} \mathrm{~s}^{-1}$ & Nordsveen [10] \\
\hline$D_{\mathrm{H} 2 \mathrm{CO} 3}=2.00 \times 10^{-9} \mathrm{~m}^{2} / \mathrm{s}$ & Kvarekval [11] \\
\hline$D_{\mathrm{HCO}^{-}}{ }^{-}=1.105 \times 10^{-9} \mathrm{~m}^{2} / \mathrm{s}$ & Newman [12] \\
\hline$D_{H}^{+}=9.312 \times 10^{-9} \mathrm{~m}^{2} / \mathrm{s}$ & Newman \\
\hline$D_{\mathrm{CO} 3}=0.92 \times 10^{-9} \mathrm{~m}^{2} / \mathrm{s}$ & Kvarekval \\
\hline
\end{tabular}
concentration value of $1 \times 10^{-9} \mathrm{~mol} / \mathrm{L}$ and $\mathrm{H}^{+}$concentration value of $1 \times 10^{-6} \mathrm{~mol} / \mathrm{L}$ are measured and calculated by coal chemical companies.

Table 2. Constant for the model.

Note: In the table, $T_{f}$ is temperature in degrees Fahrenheit, $T$ is absolute temperature in Kelvin, $T_{c}$ is temperature in degrees Celsius, $P$ is the absolute pressure, $D$ is the diffusion coefficient, equilibrium $(K)$ and forward $\left(k_{f}\right)$ reaction rate coefficients.

\section{Results}

\subsection{Turbulence Characteristics of Gas}

\subsubsection{Pressure, Friction Speed Characteristics, and Turbulence Intensity}

Figure $4 \mathrm{a}, \mathrm{b}$ shows the pressure distribution contour of the pipeline. Although the pressure in the entire pipe is set to a constant $(6.5 \mathrm{MPa})$, the pressure on the extrados surface $(6.51 \mathrm{MPa})$ is higher than 
that on the intrados surface (6.49 MPa). Figure 4c,d shows the distribution of the friction speed along the wall. The friction speed on the elbow surface is usually higher than that on the wall of straight sections. The friction speed on the intrados surface of elbow is higher than that on the extrados surface. The friction speed on the intrados surface of the first half of elbow is higher than that of the second half, however, the distribution of friction speed on the extrados surface is contrasting. Figure $4 \mathrm{e}, \mathrm{f}$ shows the turbulence intensity distribution of gas. The turbulence intensity is strong and complex at the elbow section. In addition, the turbulent intensity coil is formed into a concave shape in the second straight section, and the coil points to the intrados surface.

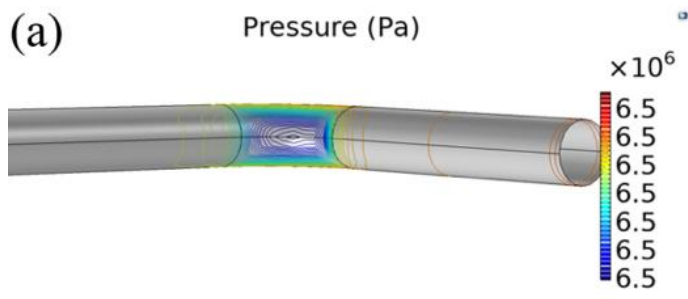

(c)

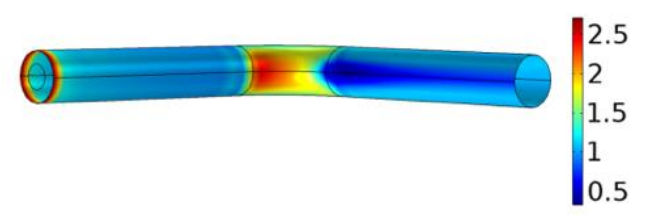

(e)

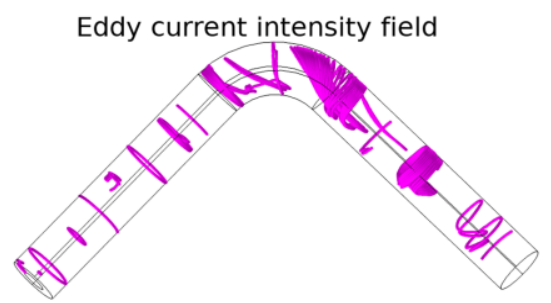

(b)

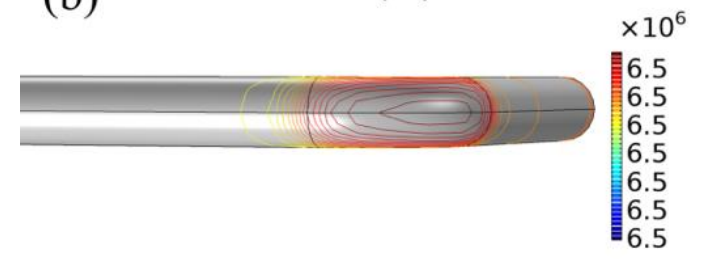

(d)

friction velocity $(\mathrm{m} / \mathrm{s})$

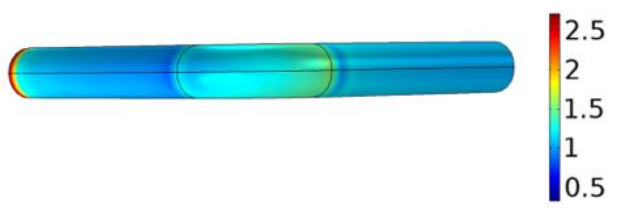

(f)

Eddy current intensity field

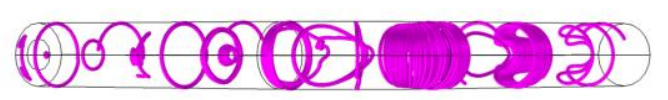

Figure 4. Turbulence characteristic. (a,b) Pressure contour at different views; (c,d) friction velocity distribution on the wall at different views; $(\mathbf{e}, \mathbf{f})$ turbulent strength at different views.

\subsubsection{Velocity Streamline in Pipeline}

Figure 5 shows the distribution of streamlines in pipeline, where the color of the streamline indicates the velocity magnitude. From Figure 5a, the maximum flow velocity $(41.01 \mathrm{~m} / \mathrm{s})$ and the minimum flow velocity $(1.609 \mathrm{~m} / \mathrm{s})$ are concentrated in the elbow section. From Figure $5 \mathrm{~b}$, the location of maximum flow velocity and minimum flow velocity is close to the intrados surface. The velocity of gas increases and then decreases near the intrados surface, however, the velocity of the gas decreases and then increases near the extrados surface. From Figure 5b,c, the streamlines gradually were concentrated and many flow lines were terminated in the second straight section. Furthermore, most of streamlines are concentrated near the intrados surface and formed a $\varepsilon$-shape distribution. From Figure $5 d$, the streamlines near the extrados in elbow are constrained by the wall and diverged into the second straight section, and the middle streamlines has a relatively high velocity. 
(a) Velocity magnitude $(\mathrm{m} / \mathrm{s})$

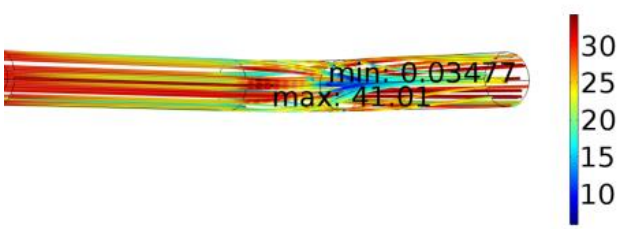

(c)

Velocity magnitude $(\mathrm{m} / \mathrm{s})$

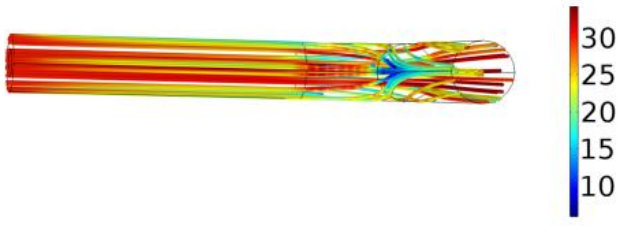

(b) Velocity magnitude $(\mathrm{m} / \mathrm{s})$

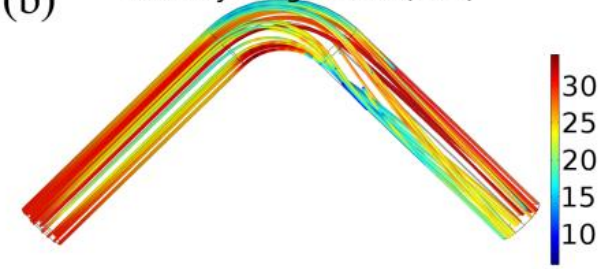

(d)

Velocity magnitude $(\mathrm{m} / \mathrm{s})$

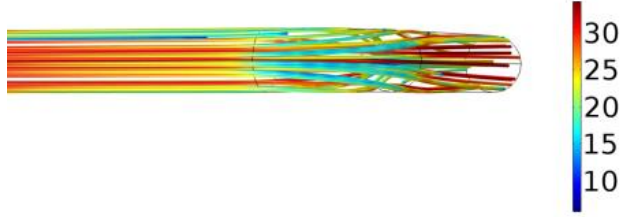

Figure 5. A three-dimensional diagram of fluid velocity distribution at different views (speed in color).

\subsubsection{Velocity along the Four Featured Edges}

Figure 6 shows a velocity diagram that indicates the variation in velocity along the four edges of pipeline. Near the inlet, the velocity along four edges drops from $30 \mathrm{~m} / \mathrm{s}$ to about $13 \mathrm{~m} / \mathrm{s}$, and then a small reduction in speed occurs in the first straight section. Near the elbow section, the flow velocity on the interior edge was subject to small fluctuations. Although the velocity magnitude of interior edge in the elbow section has increased dramatically (up to $28 \mathrm{~m} / \mathrm{s}$ ) and then undergoes a drastic reduction (low as $1 \mathrm{~m} / \mathrm{s}$ ), the flow velocity on other three edges is increased. In the second straight section, the speeds on the top and bottom edges decrease slightly and stay within a certain value, while the speed on the exterior edge still maintains an increase, and then reduced and kept consistent. On the interior edge, speed has been gradually increased to reach steady state.

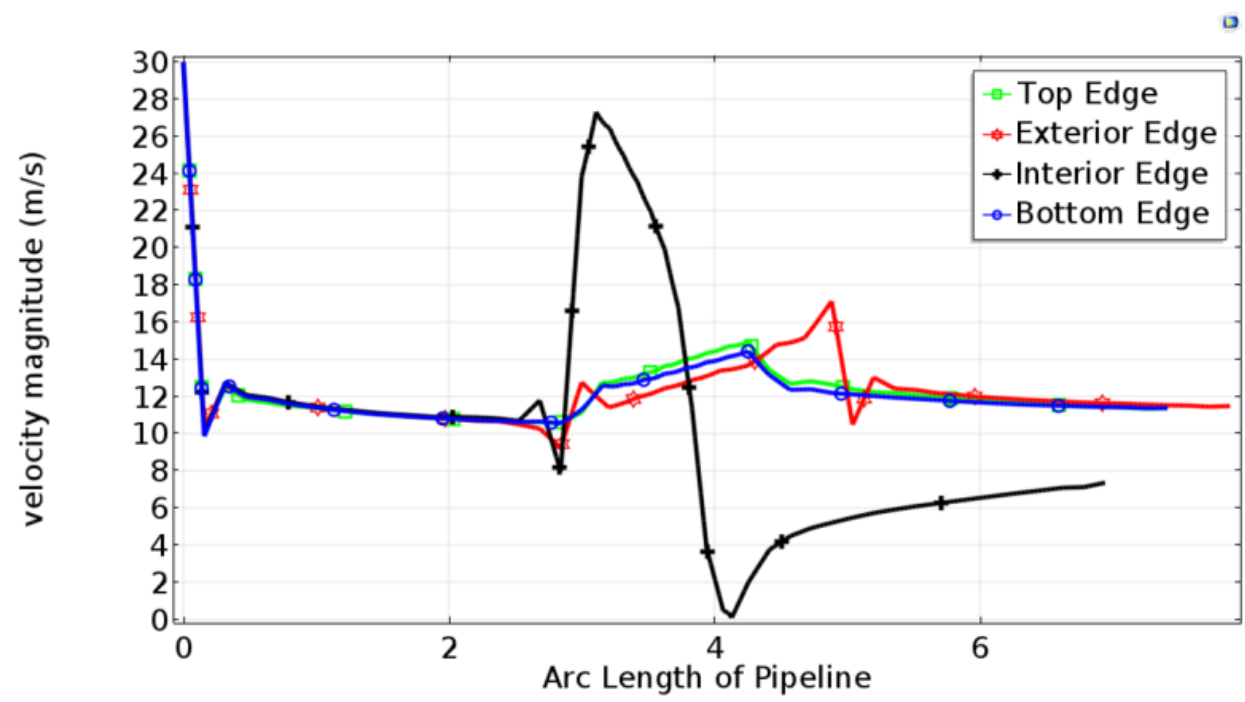

Figure 6. Line graph of velocity magnitude along four edges of pipeline.

\subsection{Electrochemical Corrosion Behavior}

\subsubsection{Species Concentration Distribution Characteristic}

Figure 7 shows the concentration distribution of chemical substances in the pipe. The concentration of substances is accumulated at the entrance of the elbow, especially near the intrados surface. 
Carbonic acid concentration reaches $443.84 \mathrm{~mol} / \mathrm{m}^{3}$. Hydrogen ion concentration is maintained at a constant value of $9.70 \mathrm{~mol} / \mathrm{m}^{3}$. The highest concentration of carbonate ions reaches $9.71 \mathrm{~mol} / \mathrm{m}^{3}$. The maximum concentration of bicarbonate ion is $5.55 \mathrm{~mol} / \mathrm{m}^{3}$. However, near the extrados surface, the accumulation of substance concentration is relatively small. All simulations were performed by the experimental parameters in Table 1.

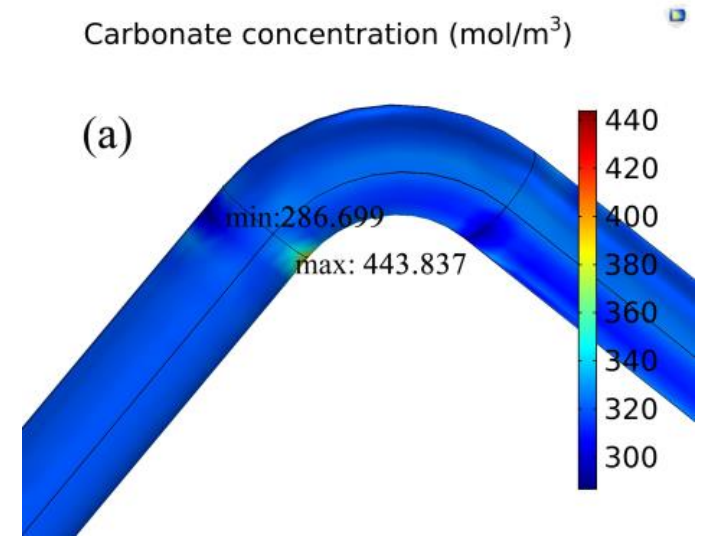

Carbonate ion concentration $\left(\mathrm{mol} / \mathrm{m}^{3}\right)$

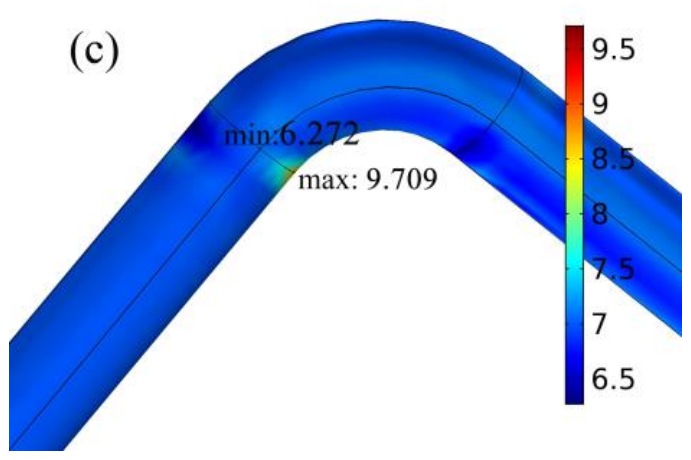

Bicarbonate concentration $\left(\mathrm{mol} / \mathrm{m}^{3}\right)$

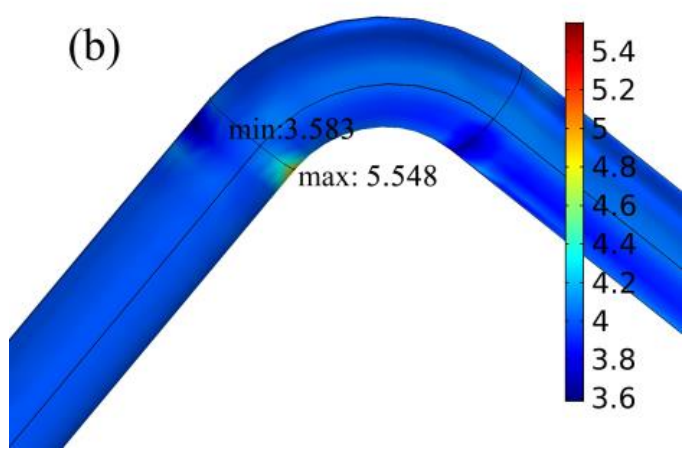

Hydrogen ion concentration $\left(\mathrm{mol} / \mathrm{m}^{3}\right)$

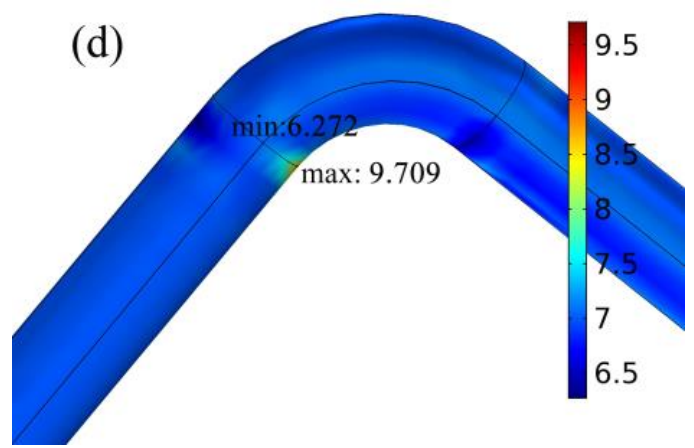

Figure 7. A three-dimensional diagram of material concentration distribution. (a) Carbonic acid concentration distribution; (b) bicarbonate concentration distribution; (c) carbonate ion concentration distribution; (d) hydrogen ion concentration distribution.

\subsubsection{Current Density Characteristic}

Figure 8 shows the variations in current density of four feature edges along the wall from the inlet to the outlet of the pipe. Figure 8a shows the total current density of the interface; Figure $8 \mathrm{~b}$ shows the anode current density and Figure $8 c$ shows the cathode current density.

\section{Total Interface Current Density of Four Edges}

From Figure 8a, the current density of four edges hardly has a difference in the first straight section. However, in the elbow section, the current density on the interior and exterior edges has a sharp fluctuation respectively. The current density on the exterior edge has a relatively positive fluctuation in the first half of elbow, and the current density on the interior edge has a negative and a positive fluctuation respectively. In the second straight section, the current density of four edges has a small fluctuation around $0 \mathrm{~A} / \mathrm{m}^{2}$. 
Anode Current Density of the Four Edges

From Figure $8 \mathrm{~b}$, the anode current density of the top and bottom edges is maintained about $4.4 \times 10^{-4} \mathrm{~A} / \mathrm{m}^{2}$ throughout the pipeline. However, the current density on the interior and exterior edges of the elbow section has a sharp fluctuation, especially on the interior edge. The anode current on the interior edge increased sharply to about $6.1 \times 10^{-4} \mathrm{~A} / \mathrm{m}^{2}$ in the first half of the elbow, then was maintained at about $4.4 \times 10^{-4} \mathrm{~A} / \mathrm{m}^{2}$, and finally decreased to $4.1 \times 10^{-4} \mathrm{~A} / \mathrm{m}^{2}$ in the second half of the elbow. The anode current density on the exterior edge decreased to $3.9 \times 10^{-4} \mathrm{~A} / \mathrm{m}^{2}$ in the first half of elbow, and then maintained a stable value at around $4.4 \times 10^{-4} \mathrm{~A} / \mathrm{m}^{2}$.

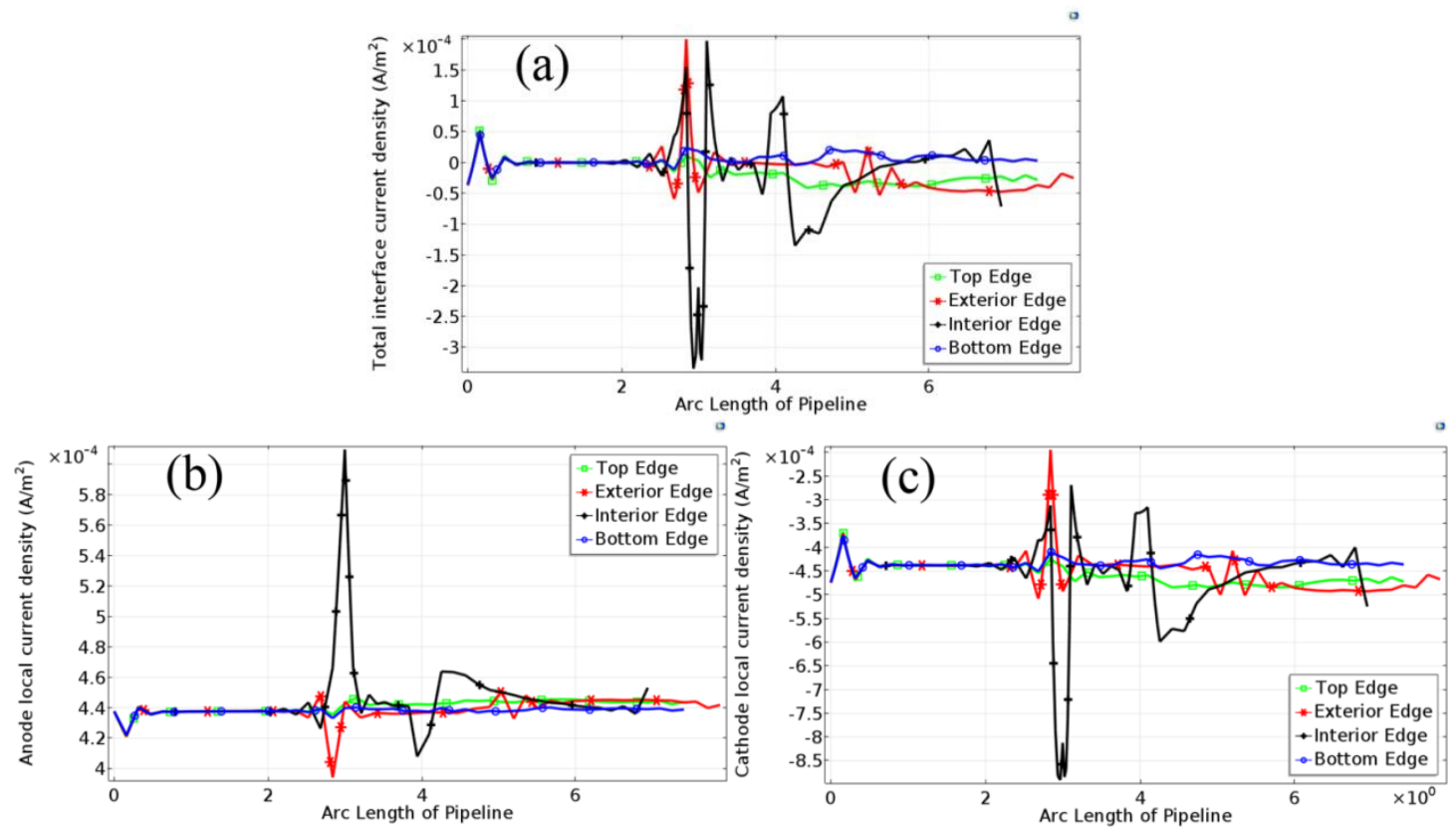

Figure 8. The current density distribution of four featured edges on the tube. (a) Total interface current density distribution; (b) anode current density distribution; (c) cathode current density distribution.

\section{Cathode Current Density of the Four Edges}

From Figure $8 \mathrm{c}$, the cathode current density of four edges in the first straight section maintains at about $-4.4 \times 10^{-4} \mathrm{~A} / \mathrm{m}^{2}$. However, in the elbow section, the current density on the interior and exterior edges has a sharp fluctuation respectively. The current density on the interior edge in the first half of elbow has a relatively negative fluctuation (about $-9.0 \times 10^{-4} \mathrm{~A} / \mathrm{m}^{2}$ ) and then in the second half of the elbow has a relatively positive fluctuation (about $-2.7 \times 10^{-4} \mathrm{~A} / \mathrm{m}^{2}$ ). The current density on the exterior edge in the first half of elbow has a positive fluctuation (about $-2.4 \times 10^{-4} \mathrm{~A} / \mathrm{m}^{2}$ ). In the second straight section, the current density on four edges has a small fluctuation around $-4.5 \times 10^{-4} \mathrm{~A} / \mathrm{m}^{2}$.

\section{Current Density Distribution on the Wall}

Figure 9 shows the current density distribution caused by electrochemical reactions under turbulence throughout the pipeline. From Figure 9a, the serious part of the total interface current density is mainly concentrated at the intersection of the elbow and the straight sections. From Figure 9b, the most serious metal loss caused by the electrochemical corrosion is concentrated at the junction of the elbow and the first straight section. From Figure 9c, the serious part of the cathode local current density is similar to the part of the total interface current density. 
(a) Total interface current density $\left(\mathrm{A} / \mathrm{m}^{2}\right)$

口

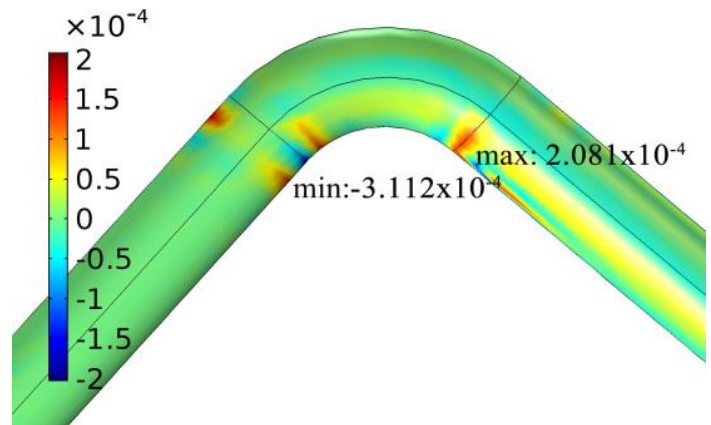

(b) Anode local current density $\left(\mathrm{A} / \mathrm{m}^{2}\right)$

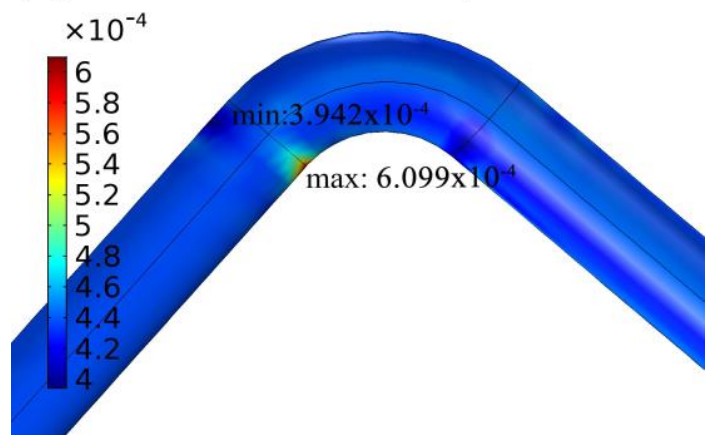

- (c) Cathode local current density $\left(\mathrm{A} / \mathrm{m}^{2}\right)$

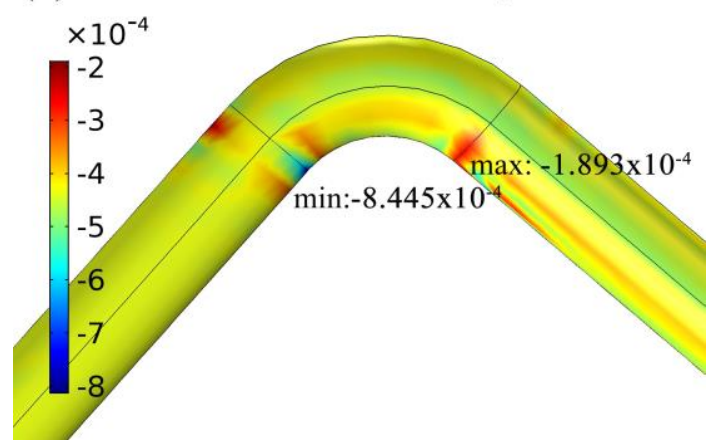

Figure 9. Current density 3D map on the wall. (a) Total interface current density; (b) anode local current density; (c) cathode local current density.

\subsection{Erosion Behavior}

\subsubsection{Particle Trajectory}

Figure 10 shows the trajectory of the particle motion in the entire pipeline and Figure 11 shows the trajectory of particle hitting the wall of the elbow, where the color of the particles indicates the velocity. Form Figure 10a,b, particles in the first straight section basically maintained the same velocity, except for particles with the minimum speed near the extrados surface. In addition, at the junctions of elbow and the first straight section, the velocity of the solid particles was changed, and particles were significantly moved toward the extrados surface. From Figure 10c, the particles in the first half of the elbow hit the extrados surface along an approximately straight line, and particles near the extrados surface were gradually pushed toward intrados surface. As shown in Figure 10c-e, many particles hit the extrados surface of elbow. As shown in Figure 11, the particles hit the elbow forming a curved distribution and bouncing off the wall. A small quantity of particles lagged near the intrados when particles are at the junction of the elbow and the second straight section. In Figure 10f-h, the motion of the particles in the second straight section gradually became more dispersive, and the particles formed the cloud cluster. 
(a)

$\mathrm{t}=0.10 \mathrm{~s}$ Particle Trajectories

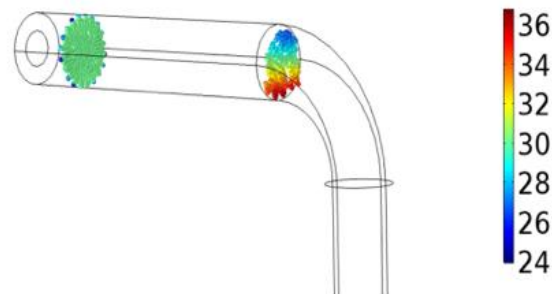

(c)

$\mathrm{t}=0.12 \mathrm{~s}$ Particle Trajectories

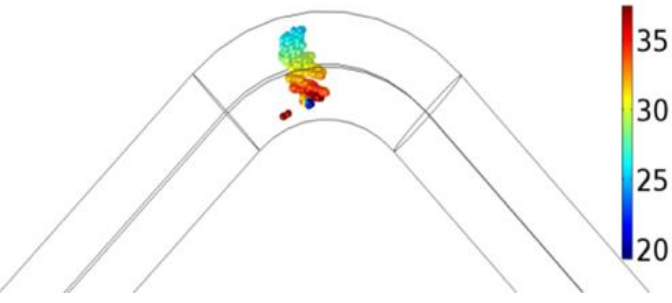

(e)

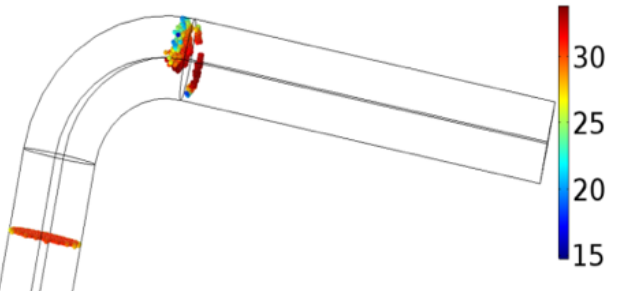

(g)

$\mathrm{t}=0.21 \mathrm{~s}$ Particle Trajectories

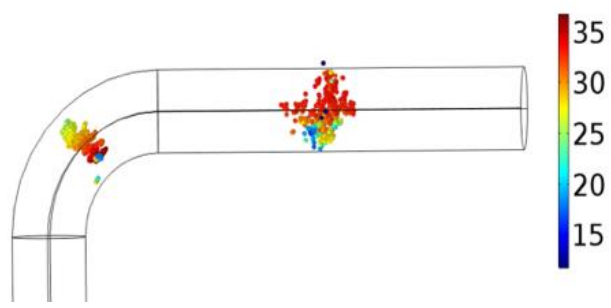

(b) $t=0.11 \mathrm{~s}$ Particle Trajectories
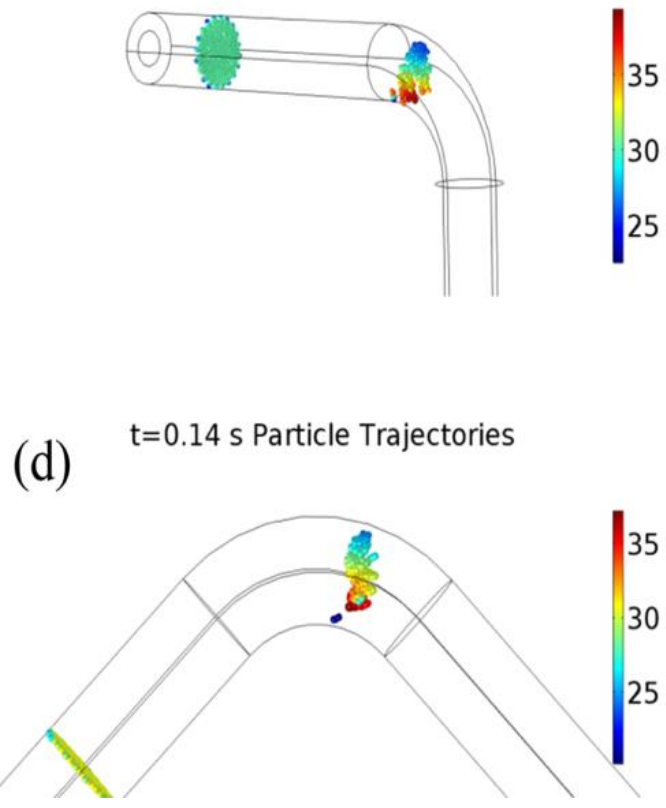

(f) $\mathrm{t}=0.18 \mathrm{~s}$ Particle Trajectories

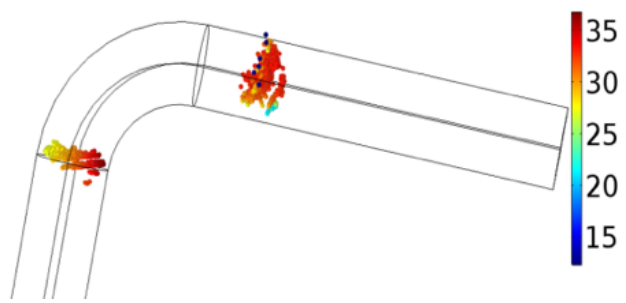

(h)

$\mathrm{t}=0.24 \mathrm{~s}$ Particle Trajectories

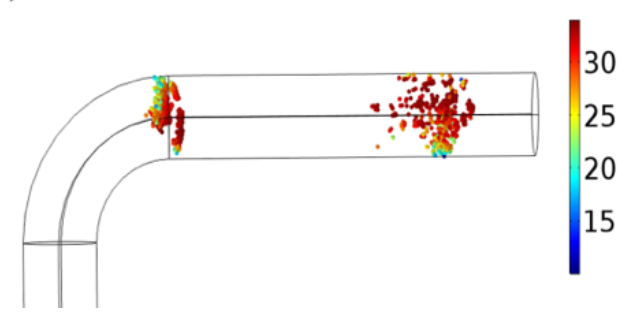

Figure 10. Three-dimensional diagram of particle trajectories in the pipeline (the color indicates the speed). (a) $\mathrm{t}=0.10 \mathrm{~s}$ particle trajectories; $(\mathbf{b}) \mathrm{t}=0.11 \mathrm{~s}$ particle trajectories; $(\mathbf{c}) \mathrm{t}=0.12 \mathrm{~s}$ particle trajectories; $(\mathbf{d}) \mathrm{t}=0.14 \mathrm{~s}$ particle trajectories; $(\mathbf{e}) \mathrm{t}=0.16 \mathrm{~s}$ particle trajectories; $(\mathbf{f}) \mathrm{t}=0.18 \mathrm{~s}$ particle trajectories; $(\mathrm{g}) \mathrm{t}=0.21 \mathrm{~s}$ particle trajectories; $(\mathbf{h}) \mathrm{t}=0.24 \mathrm{~s}$ particle trajectories. 
(a)
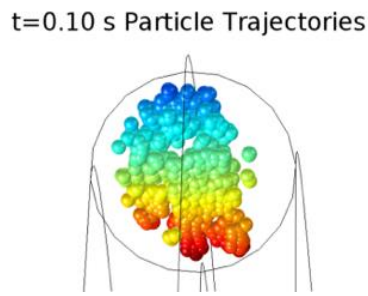

(c)

$\mathrm{t}=0.12 \mathrm{~s}$ Particle Trajectories

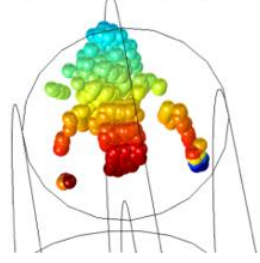

(e)
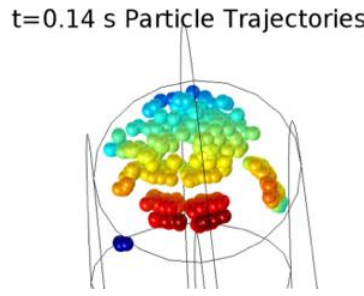

(g)

$\mathrm{t}=0.16 \mathrm{~s}$ Particle Trajectories

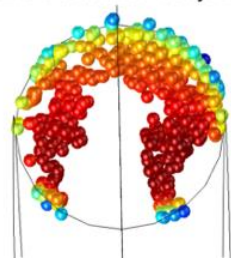

(b)

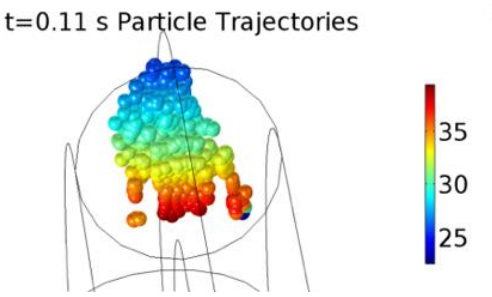

(d)

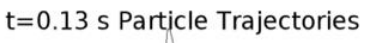

\section{5 \\ 30 \\ 25
20}

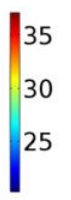

(f)
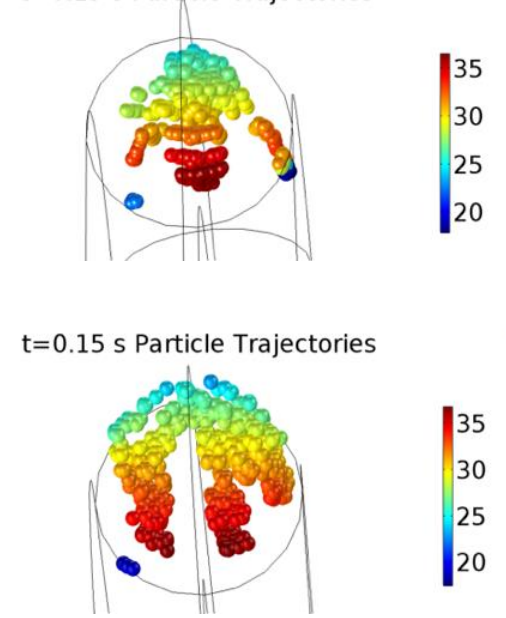

(h)

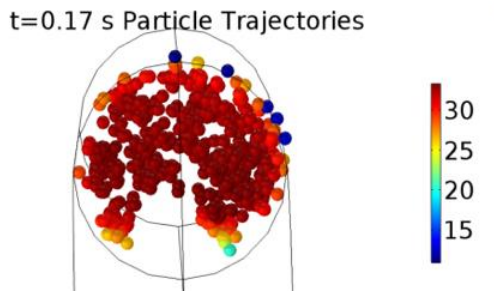

Figure 11. The trajectory of particles hitting the wall (the color indicates the speed). (a) $t=0.10 \mathrm{~s}$ particle trajectories; $(\mathbf{b}) \mathrm{t}=0.11 \mathrm{~s}$ particle trajectories; $(\mathbf{c}) \mathrm{t}=0.12 \mathrm{~s}$ particle trajectories; $(\mathbf{d}) \mathrm{t}=0.13 \mathrm{~s}$ particle trajectories; $(\mathbf{e}) \mathrm{t}=0.14$ s particle trajectories; $(\mathbf{f}) \mathrm{t}=0.15 \mathrm{~s}$ particle trajectories; $(\mathrm{g}) \mathrm{t}=0.16 \mathrm{~s}$ particle trajectories; $(\mathbf{h}) \mathrm{t}=0.17 \mathrm{~s}$ particle trajectories.

\subsubsection{The Quantities of Particles Striking the Wall and Mass Loss Per Unit Area}

Figure 12 shows the variation of quantities of particles hitting the wall. Figure 13 reveals that the variation of mass loss per unit area caused by the erosion. During the simulation, the count method is used to study the particles collision wall. The results are shown in Table 3. Numbers of solid particle collisions is around $0.2 \times 10^{4}$ of the maximum value at the straight section, and numbers of solid particle collisions is around $1.255 \times 10^{4}$ of the maximum value at the elbow. It can be concluded that approximately $16.7 \%(1 / 6)$ of the total released particles hit the extrados of the elbow and caused a serious loss of quality. As time goes on, the quantity of particles striking the wall gradually increases, accompanied by an increase in the loss of metal quality. In addition, it can be found that the mass loss per unit area mainly occurs between $40^{\circ}$ and $50^{\circ}$, with the most serious region between $43^{\circ}$ and $48^{\circ}$, and gradually was spread to the surrounding area, forming oblique elliptical erosion area. The simulation results considering the presence of acidic substances can be verified from other papers [13]. 
(a) $t=2 \mathrm{~s}$ Number of solid particle collisions

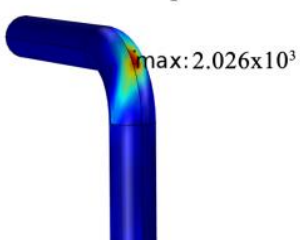

$\times 10^{3}$

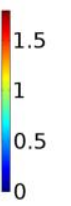

(c) $t=6 \mathrm{~s}$ Number of solid particle collisions
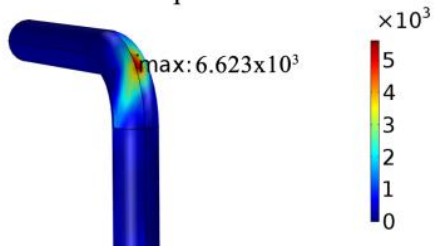

(e) $t=10$ s Number of solid particle collisions

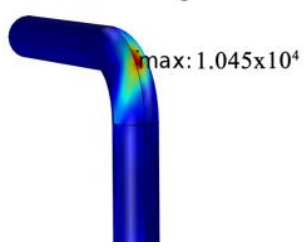

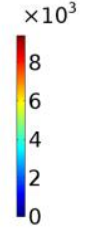

(b) $t=4$ s Number of solid particle collisions
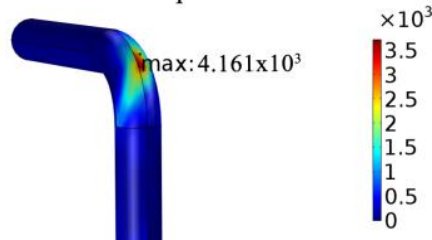

(d) $\mathrm{t}=8 \mathrm{~s}$ Number of solid particle collisions

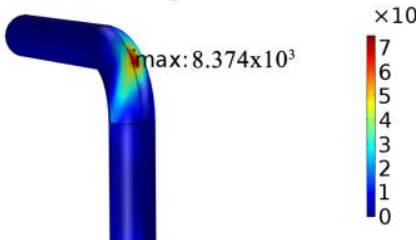

(f) $t=12 \mathrm{~s}$ Number of solid particle collisions

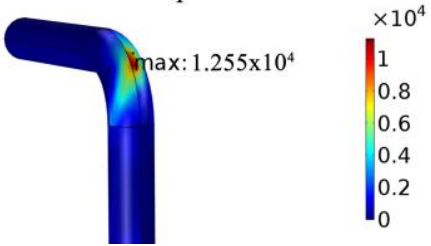

Figure 12. The number of solid particles hitting the wall. (a) $t=2 \mathrm{~s}$ number of solid particle collisions; (b) $\mathrm{t}=4 \mathrm{~s}$ number of solid particle collisions; (c) $\mathrm{t}=6 \mathrm{~s}$ number of solid particle collisions; (d) $\mathrm{t}=8 \mathrm{~s}$ number of solid particle collisions; $(\mathbf{e}) t=10$ s number of solid particle collisions; $(\mathbf{f}) t=12$ s number of solid particle collisions.

(a) $\mathrm{t}=2 \mathrm{~s}$ Mass loss per unite area $\left(\mathrm{kg} / \mathrm{m}^{2}\right)$
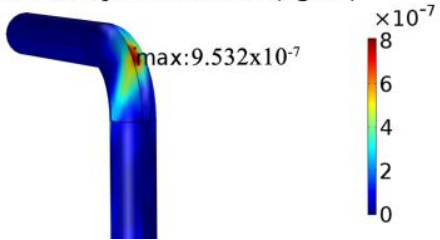

(c) $\mathrm{t}=6 \mathrm{~s}$ Mass loss per unite area $\left(\mathrm{kg} / \mathrm{m}^{2}\right)$
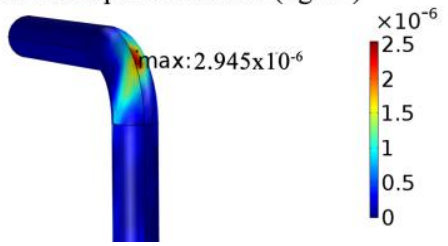

(e) $\mathrm{t}=10 \mathrm{~s}$ Mass loss per unite area $\left(\mathrm{kg} / \mathrm{m}^{2}\right)$
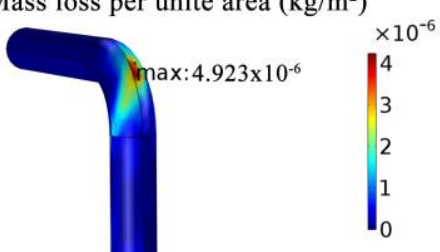

(b) $\mathrm{t}=4 \mathrm{~s}$ Mass loss per unite area $\left(\mathrm{kg} / \mathrm{m}^{2}\right)$

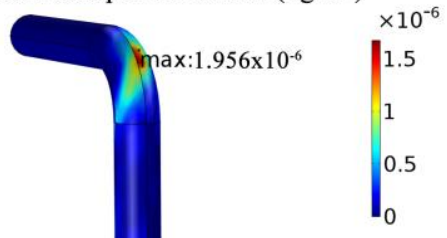

(f) $\mathrm{t}=12 \mathrm{~s}$ Mass loss per unite area $\left(\mathrm{kg} / \mathrm{m}^{2}\right)$

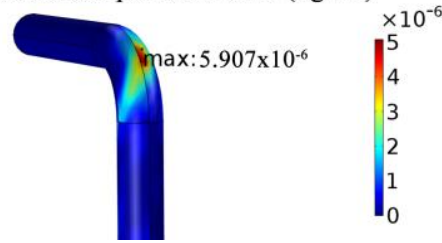

(d) $\mathrm{t}=8 \mathrm{~s}$ Mass loss per unite area $\left(\mathrm{kg} / \mathrm{m}^{2}\right)$

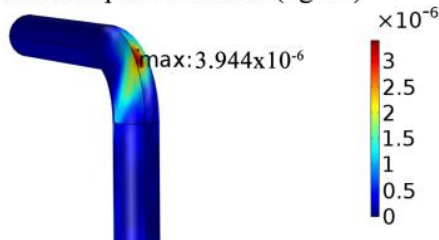

Figure 13. The evolution of mass loss per unit area $\left(\mathrm{kg} / \mathrm{m}^{2}\right)$. (a) $t=2 \mathrm{~s}$ mass loss per unit area; (b) $\mathrm{t}=4 \mathrm{~s}$ mass loss per unit area; (c) $\mathrm{t}=6 \mathrm{~s}$ mass loss per unit area; $(\mathbf{d}) \mathrm{t}=8 \mathrm{~s}$ mass loss per unit area; (e) $\mathrm{t}=10 \mathrm{~s}$ mass loss per unit area; (f) $t=12$ s mass loss per unit area. 
Table 3. Particle collision data over time.

\begin{tabular}{ccccc}
\hline Time & $\begin{array}{c}\text { The Total Number } \\
\text { of Particles in the } \\
\text { Pipeline }\end{array}$ & $\begin{array}{c}\text { The Number of } \\
\text { Particles Hitting } \\
\text { the Extrados }\end{array}$ & $\begin{array}{c}\text { Statistical } \\
\text { Probability of } \\
\text { Collision }\end{array}$ & $\begin{array}{c}\text { Maximum of Mass Loss per } \\
\text { Unite Area on the Extrados } \\
\left.\mathbf{( k g}_{\mathbf{~ m}} \mathbf{2}\right)\end{array}$ \\
\hline $2 \mathrm{~s}$ & 12,500 & 2026 & $16.2 \%$ & $9.53 \times 10^{-7}$ \\
$4 \mathrm{~s}$ & 25,000 & 4161 & $16.6 \%$ & $1.96 \times 10^{-6}$ \\
$6 \mathrm{~s}$ & 37,500 & 6263 & $16.7 \%$ & $2.95 \times 10^{-6}$ \\
$8 \mathrm{~s}$ & 50,000 & 8374 & $16.75 \%$ & $3.94 \times 10^{-6}$ \\
$10 \mathrm{~s}$ & 62,500 & 10,450 & $16.72 \%$ & $4.92 \times 10^{-6}$ \\
$12 \mathrm{~s}$ & 75,000 & 12,550 & $16.73 \%$ & $5.91 \times 10^{-6}$ \\
\hline
\end{tabular}

\section{Discussions}

Pipeline is an important part of equipments, which is widely used in petrochemical, aerospace, and other industrial applications, and is extremely important in safe production. There are unavoidable erosion and corrosion during applications, which maybe lead to leakage of the pipeline because of harsh working environments [14-18]. The main reasons of leakage are erosion, electrochemical corrosion, turbulent and chemistry, and their interactions. Corrosion is one of the most damaging mechanisms in many engineering materials and structures. Erosion of the pipelines may result in the failure of the piping system, which can be extremely dangerous and expensive. Erosion may enhance corrosion and corrosion may enhance the erosion rate through preferential dissolution and this is the so-called synergistic effect. It is well-known that, because of the synergistic effect, the possibilities of leakage are generally much higher than the sum of pure electrochemical corrosion and pure mechanical erosion. Moreover, elbows are the weak parts of gathering and transferring pipelines. In studies of erosion-corrosion there are no models available which attempt to combine the effects of particle erosion, electrochemical corrosion, chemistry, and fluid flow [19]. Nowadays, because of a strong demand for the analysis of erosion-corrosion problems, this study focuses on the following aspects: numerical study on the fluid flow, erosion, and corrosion along the axial direction of the pipeline for the real field cases and the related phenomenon of erosion-corrosion expecting to provide detailed and reasonable analysis of the failure incurred by the erosion-corrosion.

\subsection{The Correlation between Streamline and Turbulence}

Although the problems caused by the synergistic effect of erosion-corrosion are serious, the erosion-corrosion mechanism of the elbow, as influenced by the velocity and pressure, is still not thoroughly understood because of its complexity. Numerical simulations are often used in erosion-corrosion research [20]. The velocity difference on the four featured edges near the inlet is due to high wall lift force. The slow decline of speed in the first straight section is attributed to the fact that the characteristics of the boundary layer flow field and the turbulent core area is quite different. Boundary layer has blocking effect on the fluid motion and the gradient of each flow parameter is very large leading to the formation of lift and affects the velocity of the wall.

However, as a result of the variation of pressure and turbulent intensity, the speed on four edges has different fluctuations throughout the elbow. The pressure variation, as shown in Figure $4 a, b$, is ascribed to the cause that constraint in geometry results in the gases to accumulate in the elbow section, and the accumulative effect exerts a relatively high pressure on the extrados and moderately relieves the pressure on the intrados. The intense turbulent intensity are due to the truth that low viscosity of gas causes vertical flow of gas: the fluid here produces an axial velocity and a radial velocity perpendicular to the tangential velocity of the main gas flow under centrifugal force. Because the very various velocity of the fluid causes different centrifugal forces in the elbow, so here the fluid exhibits complex three-dimensional motion characteristics. The research indicates that the places of pipeline including connection affect the erosion-corrosion behaviors [21]. The change in geometry causes a sharp change in the direction of flow with a large variation in velocity and friction action or retardation 
on wall surface. As shown in Figure $4 c, d$, in the elbow section, the gases were forced to change direction with high friction velocity, which affects the fluid motion and causes low speed near the interior surface. The reduction in the amount of streamline may be due to the intense turbulence in the elbow that causes the gas movement to concentrate in some streamlines in the second straight section.

In the second straight section, the effect of turbulence intensity still affects the motion of gas, but the movement will gradually become stable along with the distance increased and the turbulence intensity dissipated.

\subsection{The Correlation of the Electrochemical Corrosion with Material Concentration Distribution}

The model includes the electrolyte domain and the electrode surface. The concentration distribution of substances produced by carbonic acid ionization reactions is mainly concentrated at the junction of the elbow and the first straight section where turbulence intensity dramatically increased. As shown in Figure 4e,f and Figure 7, the intense turbulent intensity at the entrance of the elbow is a barrier to mass transfer, and the substance is difficult to transfer to intense turbulence intensity region and cause substance to be accumulated. Furthermore, turbulent intensity is very complex and intense at the elbow and it causes the substance to pass quickly and the remaining influence continues to the outlet boundary. The flow field characteristics in the boundary layer play a role in retarding the transport of the material concentration, thus causing the material to accumulate near the wall surface.

The variation in the electrochemical corrosion current density is a concentration-dependent process in a local region, and electrochemical reaction depends on the charge transfer reaction between the ions in the electrolyte and the electrons on the wall. The charge is conserved throughout the process. Convection and diffusion affect the concentration distribution of substance. The electrochemical corrosion current density is related to substance concentration distribution. Therefore, high current density of anode on the interior edge and low current density of anode on the exterior edge of the elbow is related to the concentration distribution of material.

\subsection{Erosion in the Turbulence}

It is well-known that erosion has an important role in the total erosion-corrosion rates [22]. Severe erosion occurred at elbow is caused by the impact of solid particles driven by high-speed gas. At elbow, the direction and magnitude of gas was changed sharply because of the low viscosity and geometric constraint, and gas has a relatively small effect on the movement of particles. When the inertia of the solid particles is relatively large, the solid particles can pass through the streamline and hit the wall surface almost in a near linear path. For the straight sections, the random collision and erosion of the tube wall are caused by particles because of the influence of the pulsation of the flow field, but this effect is small. Therefore, the most severe erosion occurred at the elbow. In addition, the movement of the particles near the wall surface is lagged because of the boundary layer blocking effect. The geometric constraint and the effect of inertia of particles cause the particle group to form a curve near the extrados surface because of the boundary layer close to the tube wall and different turbulence characteristics.

There is an elliptically eroded area on the extrados surface of the elbow due to the presence of gravity, Brownian force, drag forces, and the turbulent intensity variations. In the first straight section, particles are gradually affected by the nature force; the trajectories of the particles gradually offset the line and gradually moved toward the extrados surface and the gravity direction. At the elbow, the particles impacted the wall and reduced their kinetic energy, which resulted in the subsequent particle group to be pushed and accumulated. In addition, the drastic changes in the flow direction, and the increase in turbulence intensity, caused the particles in the boundary layer to hit the wall surface and to be scratched along the wall surface, resulting in an elliptical erosion region from the bottom area to the top area. In addition, the formation of the cloud cluster in the second straight section is because the particles have different velocity directions and magnitudes at the entrance, which is affected by the wall constraint and high turbulence intensity at the elbow. 


\section{Conclusions}

Erosion-corrosion behaviors of elbow are simulated and the model containing erosion, electrochemistry corrosion, turbulence, and chemistry is built to describe the complicated failure phenomena. The conclusions are summarized as follows:

1. The serious erosion of elbow occurs between $40^{\circ}$ and $50^{\circ}$, and gradually expanded into the surrounding area forming a slanted erosion region under the force, boundary layer's blocking action and wall rebound. The particles at high speed hit the wall of the tube, especially in the elbow section with high turbulent intensity, which caused the serious erosion area on the extrados of elbow.

2. The particles count method is proposed to describe erosion and provide a probability prediction of the elbow lifetime. About 16.7\% particles collided the extrados surface during erosion.

3. The corrosion current density of iron is concentrated in the junction of the straight section and elbow and the intersection of the straight section and the intrados surface of elbow. The strong turbulent intensity in elbow and the boundary layer affects the substance concentration of chemical reactions accumulated at the junction of the straight section and elbow.

4. The pressure on the extrados is higher than that on the intrados. However, the friction speed on the intrados is higher than that on the extrados due to the cumulative effect of gas in pipe. Low viscosity of gas and the geometric constraints are attributed to cause difference in the velocity magnitude and particles hitting the wall in straight line.

Author Contributions: Q.Z. conceptualized the study and administered the project; Q.Z. and W.Q. performed the simulations; Q.Z. and W.Q. analyzed the data and wrote the manuscript; Q.Z. revised this article. All authors have read and agreed to the published version of the manuscript.

Funding: The present work is financially supported by the key project of Shaanxi province Science and Technology Department (2017ZDXM-GY-115) and National Natural Science Foundation of China (51675409), Natural Science Basic Research Plan in Shaanxi Province of China (2019JM-274) and the Open Project Program of Beijing Key Laboratory of Pipeline Critical Technology and Equipment for Deepwater Oil \& Gas Development (Grant No. BIPT2018001).

Acknowledgments: The author would like to thank the Shaanxi Special Equipment Research Institute and coal gasification companies in northern Shaanxi for the valuable data. At the same time, thanks to all the funds provided.

Conflicts of Interest: The authors declare no conflict of interest.

\section{References}

1. Rajahram, S.; Harvey, T.; Wood, R. Erosion-corrosion resistance of engineering materials in various test conditions. Wear 2009, 267, 244-254. [CrossRef]

2. De Waard, C.; Lotz, U.; Milliams, D. Predictive model for $\mathrm{CO}_{2}$ corrosion engineering in wet natural gas pipelines. Corrosion 1991, 47, 976-985. [CrossRef]

3. Liang, G.; Peng, X.; Xu, L.; Cheng, Y.F. Erosion-corrosion of carbon steel pipes in oil sands slurry studied by weight-loss testing and CFD simulation. J. Mater. Eng. Perform. 2013, 22, 3043-3048. [CrossRef]

4. Liu, H.; Zhou, Z.; Liu, M. A probability model of predicting the sand erosion profile in elbows for gas flow. Wear 2015, 342, 377-390. [CrossRef]

5. Zeng, L.; Shuang, S.; Guo, X.P.; Zhang, G.A. Erosion-corrosion of stainless steel at different locations of a 90 elbow. Corros. Sci. 2016, 111, 72-83. [CrossRef]

6. Finnie, I. Some observations on the erosion of ductile metals. Wear 1972, 19, 81-90. [CrossRef]

7. Patterson, C.S.; Slocum, G.H.; Busey, R.H.; Mesmer, R.E. Carbonate equilibria in hydrothermal systems: First ionization of carbonic acid in $\mathrm{NaCl}$ media to $300^{\circ} \mathrm{C}$. Geochim. Cosmochim. Acta 1982, 46, 1653-1663. [CrossRef]

8. Nesic, S.; Postlethwaite, J.; Olsen, S. An electrochemical model for prediction of corrosion of mild steel in aqueous carbon dioxide solutions. Corrosion 1996, 52, 280-294. [CrossRef] 
9. Oddo, J.; Tomson, M. Simplified calculation of $\mathrm{CaCO}_{3}$ saturation at high temperatures and pressures in brine solutions. J. Pet. Technol. 1982, 34, 1583-1590. [CrossRef]

10. Nordsveen, M.; Nešic, S.; Nyborg, R.; Stangeland, A. A mechanistic model for carbon dioxide corrosion of mild steel in the presence of protective iron carbonate films-Part 1: Theory and verification. Corrosion 2003, 59, 443-456.

11. Kvarekval, J. A kinetic model for calculating concentration profiles and fluxes of $\mathrm{CO}_{2}$-related species across the nernst diffusion layer. In Corrosion 97, March 9-14, 1997; NACE International: New Orleans, LA, USA, 1997.

12. Newman, J.; Thomas-Alyea, K. Electrochemical Systems; John Wiley \& Sons: Hoboken, NJ, USA, 2012.

13. Zhang, E.; Zeng, D.; Zhu, H.; Li, S.; Chen, D.; Li, J.; Ding, Y.; Tian, G. Numerical simulation for erosion effects of three-phase flow containing sulfur particles on elbows in high sour gas fields. Petroleum 2018, 4, 158-167. [CrossRef]

14. Xu, Y.; Tan, M. Probing the initiation and propagation processes of flow accelerated corrosion and erosion corrosion under simulated turbulent flow conditions. Corros. Sci. 2019, 151, 163-174. [CrossRef]

15. Zhao, J.; Xiong, D.; Gu, Y.; Zeng, Q.; Tian, B. A comparative study on the corrosion behaviors of X100 steel in simulated oilfield brines under the static and dynamic conditions. J. Pet. Sci. Eng. 2019, 173, 1109-1120. [CrossRef]

16. Islam, M.A.; Farhat, Z.N.; Ahmed, E.M.; Alfantazi, A.M. Erosion enhanced corrosion and corrosion enhanced erosion of API X-70 pipeline steel. Wear 2013, 302, 1592-1601. [CrossRef]

17. Wood, R.J.K.; Wharton, J.A.; Speyer, A.J.; Tan, K.S. Investigation of erosion-corrosion processes using electrochemical noise measurements. Tribol. Int. 2002, 35, 631-641. [CrossRef]

18. Zeng, L.; Chen, G.; Chen, H. Comparative study on flow-accelerated corrosion and erosion-corrosion at a 90 carbon steel bend. Materials 2020, 13, 1780. [CrossRef] [PubMed]

19. Stack, M.; Abdelrahman, S.; Jana, B. A new methodology for modelling erosion-corrosion regimes on real surfaces: Gliding down the galvanic series for a range of metal-corrosion systems. Wear 2010, 268, 533-542. [CrossRef]

20. Liu, J.; BaKeDaShi, W.; Li, Z.; Xu, Y.; Ji, W.; Zhang, C.; Cui, G.; Zhang, R. Effect of flow velocity on erosion-corrosion of 90-degree horizontal elbow. Wear 2017, 376, 516-525. [CrossRef]

21. Jianwen, Z.; Aiguo, J.; Yanan, X.; Jianyun, H. Numerical investigation on multiphase erosion-corrosion problem of steel of apparatus at a well outlet in natural gas production. J. Fluids Eng. 2018, 140. [CrossRef]

22. Okhovat, A.; Heris, S.Z.; Asgarkhani, M.H.; Fard, K.M. Modeling and simulation of erosion-corrosion in disturbed two-phase flow through fluid transport pipelines. Arab. J. Sci. Eng. 2014, 39, 1497-1505. [CrossRef] 